\title{
Histological Analysis and Morphometric Changes after Autologous Fat Grafting in Large Volumes on Pigs
}

\author{
Hector Giancarlo Torres-Nuño ${ }^{1}$, Walter Angel Trujillo-Rangel ${ }^{1}$, Jorge Barrera-Alcocer ${ }^{2}$, \\ Miriam Méndez del Villar'3, Diana Mercedes Hernández-Corona ${ }^{3}$, \\ Sylvia Elena Totsuka-Sutto1, Leonel García Benavides ${ }^{3 *}$ (1)
}

${ }^{1}$ Institute of Therapeutics and Clinical Experimentation, Department of Physiology, Health Sciences University Center (CUCS), University of Guadalajara (UDG), Guadalajara, Mexico

${ }^{2}$ Obesity and Diabetes Research Laboratory, Faculty of Chemistry and Biological Sciences, Autonomous University of Guerrero (UAGro), Chilpancingo, Mexico

${ }^{3}$ Multidisciplinary Health Research Center, Biomedical Sciences Department, Tonala University Center (CUT), University of Guadalajara (UDG), Guadalajara, Mexico

Email: *drleonelgb@hotmail.com

How to cite this paper: Torres-Nuño, H.G., Trujillo-Rangel, W.A., Barrera-Alcocer, J., Méndez del Villar, M., Hernández-Corona, D.M., Totsuka-Sutto, S.E. and García Benavides, L. (2021) Histological Analysis and Morphometric Changes after Autologous Fat Grafting in Large Volumes on Pigs. Journal of Cosmetics, Dermatological Sciences and Applications, 11, 371-380.

https://doi.org/10.4236/jcdsa.2021.114030

Received: October 26, 2021

Accepted: December 27, 2021

Published: December 30, 2021

Copyright $\odot 2021$ by author(s) and Scientific Research Publishing Inc. This work is licensed under the Creative Commons Attribution International License (CC BY 4.0).

http://creativecommons.org/licenses/by/4.0/ (c) (i) Open Access

\begin{abstract}
Nowadays, fat transfer is an accepted technique that has been popularized in clinical practice, during which large volumes of fat are strategically relocated to increase and improve the contour of the body. In the present study, we investigated the histological and morphometric changes after large volumes of fat were grafted within the subcutaneous cellular tissue. An experimental study was designed using four 3-month-old male pigs. One hundred $\mathrm{cc}$ of decanted fat tissue was transferred into the right leg. Volume augmentation achieved by auto lipo-injecting within the subcutaneous cellular tissue persisted up to two months. Although there is a reduction in cell number and size, an increased amount of extracellular matrix and the presence of oily cysts and microcalcifications were observed. Conclusion: The volume augmentation, which is achieved by autologous fat transfer in large quantities in subcutaneous cellular tissue, can remain for months.
\end{abstract}

\section{Keywords}

Autologous Fat Transfer, Adipose Tissue Transplant, Autologous Fat Injection, Gluteal Augmentation

\section{Introduction}

During the last decade, liposuction has become popular as a method of achieving 
a better body contour. Different techniques have increased the safety of this procedure [1]. However, the practice of liposuction has surpassed the knowledge of the basic principles of the biological processes occurring in the body after this procedure. Some reports have documented variations in survival of fat tissue depending on the diameter of the cannula [2], the negative pressure used to release Fat tissue from various depots throughout the body [3], and the manipulation technique used (either centrifugation or decantation) to isolate adipose cells [4]. Several authors have shown survival of Fat tissue after transferring it to muscle using small-sized cannulas and small volumes of fat [5] [6] [7] [8] [9]. However, in clinical practice, large volumes of fat tissue are placed to enhance the body contour, especially for gluteal augmentation [10]. This practice has resulted in an increase in the quantity of transferred fat tissue and has changed the plane where it is deposited. All these procedures are performed to avoid damage to vascular and nervous structures and fat embolism [11]. Recently, subcutaneous tissue has been used to deposit high volumes of fat tissue, and this has been found to reduce the above-mentioned risks. In Mexico, transfer of Fat tissue is highly effective and performed by most surgeons in gluteal enlargement procedures. Studies have shown persistent fat graft using image analysis [12]. Therefore, in the present study, we investigated the histological and morphometric changes two months after large volumes of fat grafting within the subcutaneous cellular tissue in an experimental model.

\section{Materials and Methods}

An experimental study was designed using four 3-month-old male pigs that weighed between 45 to $50 \mathrm{~kg}$. The protocol was reviewed and approved by the Bioethics and Investigation Committee of the University of Guadalajara. The pigs were provided by Forage Company (Forrajes Torres Guadalajara, Jalisco México). All pigs were under veterinary surveillance and were subjected to a quarantine period before the surgical procedure. Food and water were supplied ad libitum during the study, stopping the supply 12 hours before surgery.

\subsection{Anesthetic Procedure}

The pigs were sedated using $0.1 \mathrm{~mL} / \mathrm{kg}$ of intramuscular xylazine, and general anesthesia was induced and maintained with $0.1 \mathrm{~mL} / \mathrm{kg}$ of Zoletile 100 (Virbac Company, Guadalajara, Mexico) through an intravenous route ( $1 \mathrm{~mL}$ of Zoletile 100 contains $50 \mathrm{mg}$ tiletamine and $50 \mathrm{mg}$ zolazepam) per $\mathrm{mL}$ after dilution of all the components.

\subsection{Experimental Procedure}

The pigs were first bathed with soap and running water. After the bath, antisepsis was performed using iodopovidone and sterile water. Local infiltration was performed through a $3-\mathrm{mm}$ incision using a cannula of $2 \mathrm{~mm}$, and we administered $500 \mathrm{cc}$ of saline solution with $1 \mathrm{mg}$ of epinephrine $(1: 50,000)$. Saline solu- 
tion was dispersed with cannulas of $4 \mathrm{~mm}$ and 60 -cc syringe as much as possible to obtain a large area in the trunk and around the neck in preparation for the procedure. Bleeding was avoided by waiting for 5 minutes after the injection of the epinephrine. A 4-mm cannula that was connected to a 60-cc syringe to exert negative pressure was used to harvest the maximum amount of fat tissue, which is the routine procedure for liposuction. The harvested fat tissue was left to settle for 20 minutes before being decanted. A total of $100 \mathrm{cc}$ of fat tissue was placed into the upper inner right leg using the same cannula that was used to harvest it. During this placement, the fat was dispersed around a designated area, and saline solution without fat tissue was injected and dispersed in the contralateral side as a control. The wounds were sutured using absorbable sutures. After the surgery, antibiotic prophylaxis and analgesia were provided using $1 \mathrm{~mL}$ of Diclopenil L.A., Intramuscular injection, single-dose, each vial containing a combination of benzathine $(3,000,000 \mathrm{IU})$, procaine $(1,000,000 \mathrm{IU})$, and potassium penicillin G (2,000,000 IU), with streptomycin $(2500 \mathrm{mg})$, to be reconstituted with sodium diclofenac (250 mg), excipient $15 \mathrm{~mL}$ (Virbac Company, Guadalajara, Mexico). The pigs were clinically evaluated every day for 8 weeks. After this period, the pigs were sacrificed under general anesthesia using potassium chloride in compliance with the international guidelines for care of experimental animals. Specimens were obtained and placed in $10 \%$ formaldehyde until histological analysis (Figure 1).

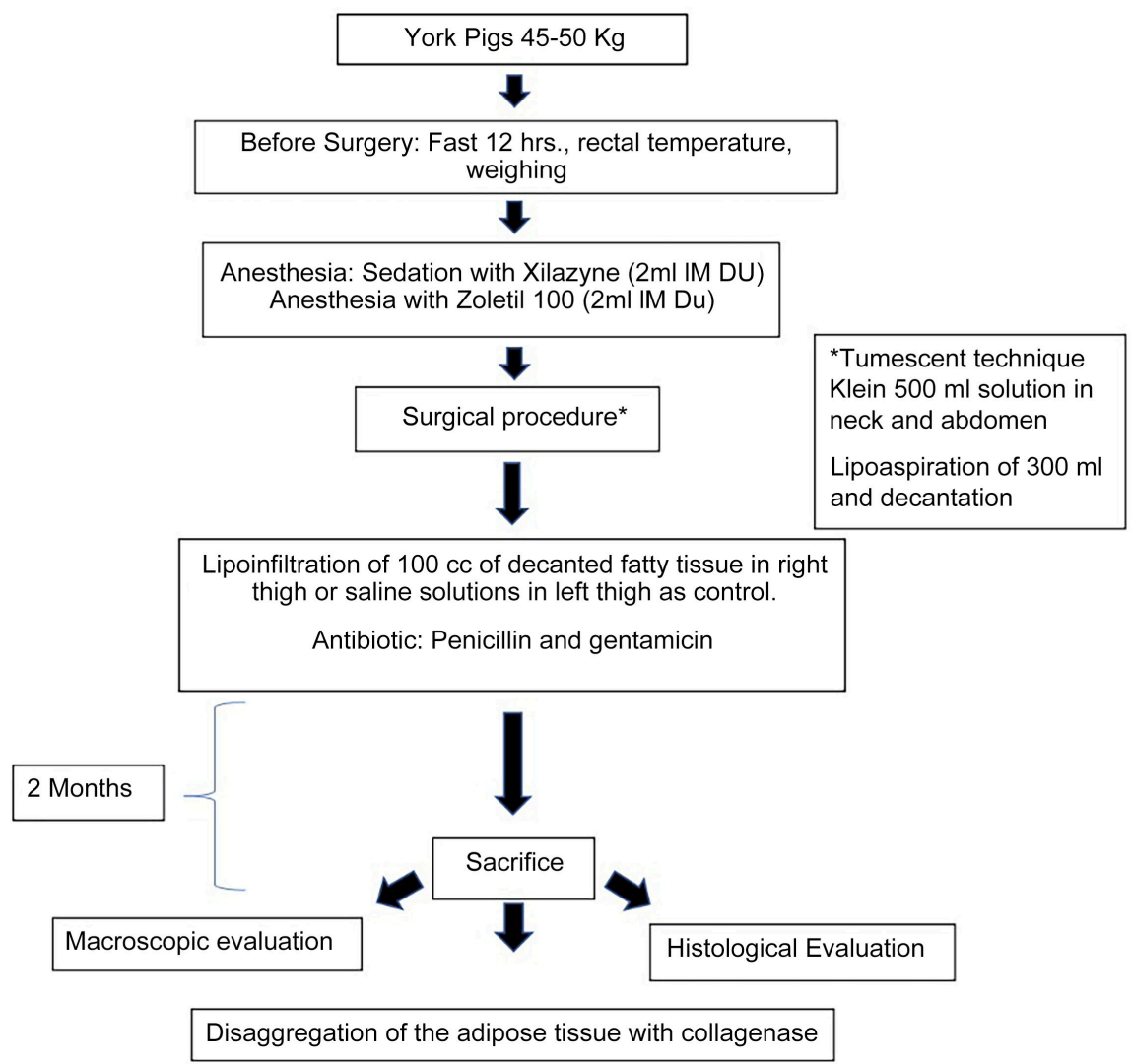

Figure 1. Experimental procedure. 


\subsection{Fat Cells Desegregation}

Following the working methods of Serna Cuellar E. [13] Fat tissue that was obtained through liposuction was centrifuged at $1200 \mathrm{rpm}$ for 2 minutes at room temperature. This resulted in three different phases: a superior phase (lipids and dead cells), an intermediate phase (live cells), and an inferior phase (remains of red bloods cells and the physiological solution of the infiltration). Tissue that was obtained from the intermediate phase was disintegrated using type 1 collagenase enzyme $\left(\mathrm{Gibco}^{\circledR}\right)$ in HEPES

(4-(2-hydroxyethyl)-1-piperazineethanesulfonic acid)buffer (Sigma-Aldrich)) and saline phosphate-buffered at $37^{\circ} \mathrm{C}$ in a water bath and manual stirring. We required different variations in the time of exposure and concentration of collagenase enzyme to achieve optimal disintegration of the tissue. We took $10 \mu \mathrm{L}$ of type 1 collagenase enzyme per $\mathrm{mL}$ of harvested fat tissue that was obtained from the control area and $30 \mu \mathrm{L}$ of type 1 collagenase enzyme per $\mathrm{mL}$ of sucked up fat tissue that was obtained from the fat grafted area, after $60 \mathrm{~min}$ of exposure, the collagenase enzyme was inactivated with fetal bovine serum at $5 \%$. The samples were centrifuged for a second time at $1200 \mathrm{rpm}$ to separate and obtain a suspension of intact adipocytes. These collected cells were placed on a slide for evaluation by a phase-contrast microscope.

\subsection{Histological Analysis}

For macroscopic analysis, the tissues were photographed, measured, and trimmed to identify formation of oily cysts in both sides. For microscopic analysis, histological sections were stained with hematoxylin and eosin and Masson's trichrome to evaluate the amount of fat tissue and the presence of fibrosis, granulomas, and inflammation.

\subsection{Statistical Analysis}

The Wilcoxon signed-rank test was carried out to evaluate differences between basal and final measures. Fisher's exact test was also performed to evaluate the presence of capillaries, necrosis, fibrosis, and infection. A p value $<0.05$ was considered significant.

\section{Results}

All four pigs tolerated the procedure without any complications, such as fever, bleeding, hematoma, seroma, or infection of the wound. No fatalities occurred during the procedure. None of the pigs experienced weight loss, changes in nutritional habits, or signs of illness postoperatively. The thickness of cellular tissue in the operated side was significantly greater compared with that of the control side (Figure 2, Table 1), which was reflected in a slight increase of the thigh circumference $(32.62 \mathrm{~cm}$ versus $30.5 \mathrm{~cm})$. Entrapped necrotic tissue and oil cysts were identified on the operated side (Figure 3 ). Histological sections showed intense fibrosis, well-organized grafted tissue with clear evidence of vasculariza- 
tion, a large number of inflammatory cells, and some microcalcification; these were more evident in the operated side compared with the control side. In the control side, adipocytes showed adequate integrity, and small quantity of extracellular matrix was observed.

Table 1. The thickness of the cellular tissue.

\begin{tabular}{cccc}
\hline Pigs & Control & Experimental & p \\
\hline 1 & $2.2 \mathrm{~cm}$ & $2.7 \mathrm{~cm}$ & \\
2 & $2 \mathrm{~cm}$ & $2.8 \mathrm{~cm}$ & \\
3 & $1.6 \mathrm{~cm}$ & $2.3 \mathrm{~cm}$ & $<0.003$ \\
4 & $2.1 \mathrm{~cm}$ & $3 \mathrm{~cm}$ & \\
Mean & $1.97 \mathrm{~cm}$ & $2.7 \mathrm{~cm}$ & \\
\hline
\end{tabular}

Control Side

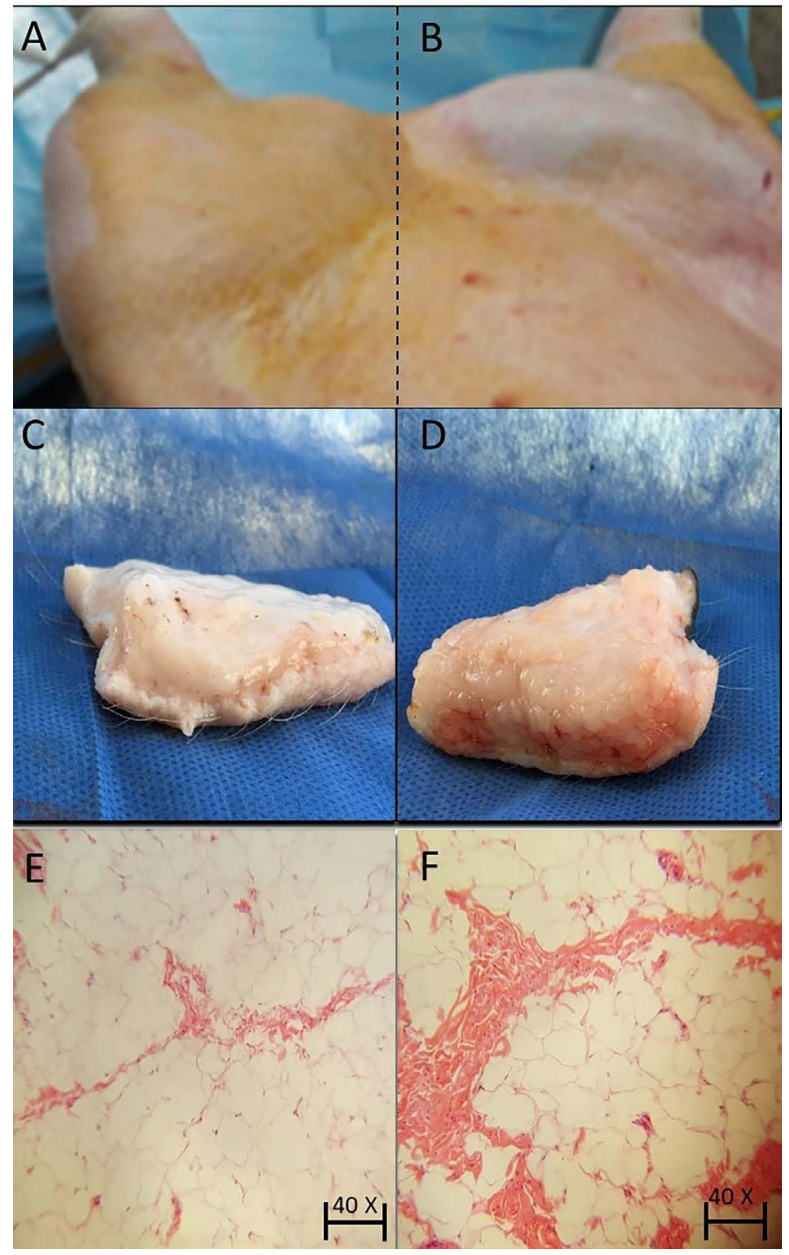

Figure 2. Comparisons of the fat grafted versus control side. (A) and (B) after surgical procedure, (C) (D). Thickness maintained two months later, (E) (F). Histological sections stained with $H \& E$ showed grafted areas with adequate integration of adipose tissue even with a significant degree of inflammatory response, also a greater amount of extracellular matrix. 


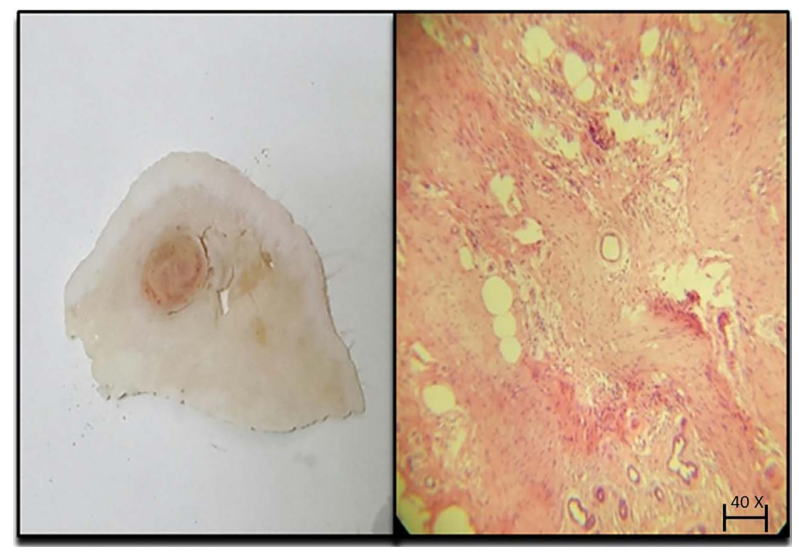

Figure 3. Focal areas of necrotic residues, with more organization and capture of waste with some microcalcifications, compared with the control group where adipocytes are observed with adequate integrity and with less extracellular matrix.

\section{Discussion}

The transfer of large volumes of fat to increase the size of the gluteal region is a technique that has become popular in recent years; however, doubts on the viability of the transplanted adipocytes persist to this day. In 1987, the American Society of Plastic and Reconstructive Surgeons estimated that only $30 \%$ of the transferred fat survived. Numerous papers have contributed to standardizing the procedures to improve adipocyte survival and have proposed detailed procedures to improve survival of grafted fat tissue [14]. The present study reveals the histological changes in the recipient site two months after the transfer of large volumes of autologous fat tissue into the subcutaneous cellular tissue of the gluteal region.

We evaluated the integrity of the grafted Fat tissue by comparing it with the results of previous techniques [15].

The compaction of the Fat tissue in the pigs implied a higher level of difficulty to harvest the cells compared to human patients submitted to conventional liposuction (negative pressure of $660 \mathrm{mmHg}, 4 \mathrm{~mm}$ cannula). This compaction of fat tissue was also evident in the disaggregation process since an extended period of time was required for incubation with type I collagenase (Figure 4). However, once the tissue was disaggregated, we were able to observe adipose cells of different sizes and with preserved cellular membranes.

Studies of the behavior of grafted adipose cells have shown that outcomes may vary according to the location in the receptor site; adipocytes that are located in the peripheral area of the grafted tissue (100 - $300 \mu \mathrm{m}$ in thickness) are alive and reside in the survival region, and the rest of the adipocytes die within the next 24 hours after the procedure [16]. These adipocytes are located in two different regions; a regeneration zone and a necrotic zone. Dead adipocytes are surrounded by macrophages, but phagocytosis takes weeks or even months, depending on the size of the dead adipocytes. This is the reason the grafted tissue maintains its original size for the first 4 weeks after the procedure [17]. 


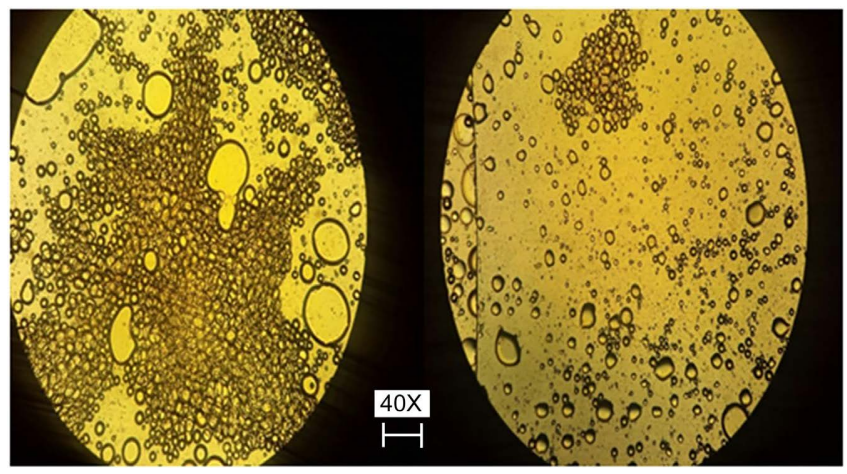

Figure 4. The sample was incubated for $12 \mathrm{~h}$, and centrifuged at $1200 \mathrm{rpm}$ for $10 \mathrm{~min}$ to separate and obtain a suspension of intact adipocytes, which were observed under a microscope for the evaluation of membrane integrity and the fatty graft shape.

Adipose-derived stem cells in the necrotic and regeneration zone are activated and start to repair tissue [18]. Nevertheless, previous studies have not demonstrated the microscopic aspects of the behavior of fat tissue grafted in volumes that are commonly used by plastic surgeons for augmentation of structures such as the gluteus muscles. We believe that the volume augmentation that was observed in our pigs was due to viable adipocytes, as well as fibrous tissue, as shown in the histological sections. Experimental studies on mice showed that the use of normobaric oxygen at $60 \%$ for 3 days postoperatively promotes survival, regeneration, and final retention of a transplanted graft. The findings suggested a high survival rate of adipocytes and adipose-derived stem cells. These studies showed that the thickness of the survival and regeneration zones increased [19].

Furthermore, in the intense fibrosis there might have been a substantial increase in the quantity and exposure time to collagenase enzyme for disintegration of the extracellular matrix components in the grafted area.

Our animal model is unique compared with previous animal models that were specially developed to study fat grafts. Previous animal models used species of smaller size, required smaller volumes and were infiltrated in the intramuscular plane [9] [20]. Despite the small number of specimens, we should consider that each one had an experimental and a control side, with our results being consistent showcasing a clear difference between sides in all subjects. We agree with various authors that the subcutaneous cellular plane can be a good option for lipoinjection [21]. This is because, in our study, we observed persistence of the graft macroscopically and well-organized fat tissue microscopically. The inflammatory reaction persisted for several months after our procedure, similar to that described in previous studies, which in turn used smaller volumes [9]. Notably, when we used larger volumes, we observed focal areas with necrotic residues composed of entrapped adipose cells of small size and oily cysts that were surrounded by the extracellular matrix. Some microcalcification areas were found in our study, which is consistently observed in imaging diagnostic tests, and it represents a cautionary suggestion in considering fat transfer as a proce- 
dure for increasing the size of the breast [22].

Fat transfer has been gaining popularity, becoming a conventional procedure for cosmetic purposes. However, the percentage of integration of adipocytes is still a subject of discussion, with several theories trying to explain the increased volume achieved and the changes on it [23]. In this paper, we observed the same findings as other authors, which are an increased extracellular matrix, the formation of oily cysts and microcalcifications as consistent changes in all animals [16], as well as the clear reduction in cellularity and volume of adipocytes that manage to remain in the grafted area.

\section{Conclusion}

Volume augmentation, which is achieved by fat transfer in large quantities in subcutaneous cellular tissue, can remain for months. Therefore, this procedure is a viable aesthetic and reconstructive surgical option. Grafted fat tissue with adequate integrity was observed two months after the procedure, although there is a reduction in the cellular size. Fat transfer also results in a large amount of extracellular matrix, oily cysts, and microcalcification.

\section{Funder Information}

This work was performed with institutional resources to support researchers (PROSNI, University of Guadalajara).

All applicable institutional and/or national guidelines for the care and use of animals were followed.

\section{Conflicts of Interest}

The authors declare no conflicts of interest regarding the publication of this paper.

\section{References}

[1] Bellini, E., Grieco, M.P. and Raposio, E. (2017) The Science behind Autologous Fat Grafting. Annals of Medicine and Surgery, 24, 65-73.

https://doi.org/10.1016/j.amsu.2017.11.001

[2] Erdim, M., Tezel, E., Numanoglu, A. and Sav, A. (2009) The Effects of the Size of Liposuction Cannula on Adipocyte Survival and the Optimum Temperature for Fat Graft Storage: An Experimental Study. Journal of Plastic, Reconstructive \& Aesthetic Surgery, 62, 1210-1214. https://doi.org/10.1016/j.bjps.2008.03.016

[3] Leong, D.T., Hutmacher, D.W., Chew, F.T. and Lim, T.C. (2005) Viability and Adipogenic Potential of Human Adipose Tissue Processed Cell Population Obtained from Pump-Assisted and Syringe-Assisted Liposuction. Journal of Dermatological Science, 37, 169-176. https://doi.org/10.1016/j.jdermsci.2004.11.009

[4] Smith, P., Adams, W.P., Lipschitz, A.H., Chau, B., Sorokin, E., Rohrich, R.J. and Brown, S.A. (2006) Autologous Human Fat Grafting: Effect of Harvesting and Preparation Techniques on Adipocyte Graft Survival. Plastic and Reconstructive Surgery, 117, 1836-1844. https://doi.org/10.1097/01.prs.0000218825.77014.78

[5] Peer, L.A. (1950) Loss of Weight and Volume in Human Fat Grafts: With Postulation of a "Cell Survival Theory". Plastic and Reconstructive Surgery, 5, 217-230. 
https://doi.org/10.1097/00006534-195003000-00002

[6] Aygit, A.C., Sarikaya, A., Doganay, L., Top, H., Cakir, B. and Firat, M.F. (2004) The Fate of Intramuscularly Injected Fat Autografts: An Experimental Study in Rabbits. Aesthetic Plastic Surgery, 28, 334-339. https://doi.org/10.1007/s00266-004-3121-7

[7] Peer, L.A. (1946) The Neglected Free Fat Graft. Plastic and Reconstructive Surgery, 18, 233-250. https://doi.org/10.1097/00006534-195610000-00001

[8] Guerrerosantos, J., Gonzalez-Mendoza, A., Masmela, Y., Gonzalez, M.A., Deos, M. and Diaz, P. (1996) Long-Term Survival of Free Fat Grafts in Muscle: An Experimental Study in Rats. Aesthetic Plastic Surgery, 20, 403-408. https://doi.org/10.1007/BF02390315

[9] Brucker, M., Sati, S., Spangenberger, A. and Weinzweig, J. (2008) Long-Term Fate of Transplanted Autologous Fat in a Novel Rabbit Facial Model. Plastic and Reconstructive Surgery, 122, 749-754. https://doi.org/10.1097/PRS.0b013e3181815a41

[10] Peren, P.A., Gomez, J.B., Guerrerosantos, J. and Salazar C.A. (2000) Gluteus Augmentation with Fat Grafting. Aesthetic Plastic Surgery, 24, 412-417. https://doi.org/10.1007/s002660010069

[11] Rosique, R.G. and Rosique, M.J.F. (2016) Deaths Caused by Gluteal Lipoinjection. What Are We Doing Wrong? Plastic and Reconstructive Surgery, 137, 641e-642e. https://doi.org/10.1097/01.prs.0000479999.49928.38

[12] Fontdevila, J., Serra-Renom, J.M., Raigosa, M., Berenguer, J., Guisantes, E., Prades, E., Benito-Ruiz, J. and Martinez, E. (2008) Assessing the Long-Term Viability of Facial Fat Grafts: An Objective Measure Using Computed Tomography. Aesthetic Surgery Journal, 28, 380-386. https://doi.org/10.1016/j.asj.2008.05.002

[13] Serna-Cuéllar, E. and Santamaría-Solís, L. (2013) Protocol of Extraction and Processing of Adult Stem Cells from Abdominal Adipose Tissue: Coordenates of the Plastic Surgeon in Translational Researching. Cirugía Plástica Ibero-Latinoamericana, 39, S44-S50. https://doi.org/10.4321/S0376-78922013000500012

[14] Nishimura, T., Hashimoto, H., Nakanishi, I. and Furukawa, M. (2000) Microvascular Angiogenesis and Apoptosis in the Survival of Free Fat Grafts. The Laryngoscope, 110, 1333-1338. https://doi.org/10.1097/00005537-200008000-00021

[15] Kakagia, D. and Pallua, N. (2014) Autologous Fat Grafting: In Search of the Optimal Technique. Surgical Innovation, 21, 327-336. https://doi.org/10.1177/1553350613518846

[16] Kato, H., Mineda, K., Eto, H., Doi, K., Kuno, S., Kinoshita, K., Kanayama, K. and Yoshimura, K. (2014) Degeneration, Regeneration, and Cicatrization after Fat Grafting: Dynamic Total Tissue Remodeling during the First 3 Months. Plastic and Reconstructive Surgery, 133, 303e-313e. https://doi.org/10.1097/PRS.0000000000000066

[17] Phipps, K.D., Gebremeskel, S., Gillis, J., Hong, P., Johnston, B. and Bezuhly M. (2015) Alternatively Activated M2 Macrophages Improve Autologous Fat Graft Survival in a Mouse Model through Induction of Angiogenesis. Plastic and Reconstructive Surgery, 135, 140-149. https://doi.org/10.1097/PRS.0000000000000793

[18] He, X., Zhong, X., Ni, Y., Liu, M., Liu, S. and Lan, X. (2013) Effect of ASCs on the Graft Survival Rates of Fat Particles in Rabbits. Journal of Plastic Surgery and Hand Surgery, 47, 3-7. https://doi.org/10.3109/2000656X.2012.730488

[19] Kato, H., Araki, J., Doi, K., Kuno, S., Kinoshita, K., Mineda, K., Kanayama, K. and Yoshimura, K. (2014) Normobaric Hyperoxygenation Enhances Initial Survival, Regeneration, and Final Retention in Fat Grafting. Plastic and Reconstructive Surgery, 134, 951-959. https://doi.org/10.1097/PRS.0000000000000600 
[20] Guerrerosantos, J. (2005) The Fate of Intramuscularly Injected Fat Autografts: An Experimental Study. Aesthetic Plastic Surgery, 29, 62.

https://doi.org/10.1007/s00266-004-0005-9

[21] Villanueva, N.L., Del Vecchio, D.A., Afrooz, P.N., Carboy, J.A. and Rohrich, R.J. (2018) Staying Safe during Gluteal Fat Transplantation. Plastic and Reconstructive Surgery, 141, 79-86. https://doi.org/10.1097/PRS.0000000000003934

[22] Carvajal, J. and Patino J.H. (2008) Mammographic Findings after Breast Augmentation with Autologous Fat Injection. Aesthetic Surgery Journal, 28, 153-162. https://doi.org/10.1016/j.asj.2007.12.008

[23] Strong, A.L., Cederna, P.S., Rubin, J.P., Coleman, S.R. and Levi, B. (2015) The Current State of Fat Grafting: A Review of Harvesting, Processing, and Injection Techniques. Plastic and Reconstructive Surgery, 136, 897-912.

https://doi.org/10.1097/PRS.0000000000001590 